\title{
Hybrid aerogels and bioactive aerogels under uniaxial compression: an in situ SAXS study
}

\author{
V. Morales-Flórez*, N. de la Rosa-Fox**, M. Piñero*** and L. Esquivias*,****
}

\begin{abstract}
The complex structure of hybrid organic/inorganic aerogels is composed by an inorganic phase covalently bonded to an organic chain forming a copolymer. Conventional hybrid aerogels were studied as well as bioactive hybrid aerogels, that is, aerogels with a calcium active phase added. In this work, the relationship between mechanical response and nanostructure was studied, using a specifically designed sample-holder for in situ uniaxial compression obtaining at the same time the small-angle X-ray pattern from synchrotron radiation (SAXS). Structural elements can be described as a particulated silica core surrounded by the organic chains. These chains are compressed on the direction parallel to the load, and a relationship between macroscopic uniaxial compression and particle and pore deformations can be established.
\end{abstract}

Keywords Hybrid aerogel; Bioactivity; Nanostructure; Uniaxial compression; SAXS.

\section{Aerogeles híbridos y aerogeles bioactivos en compresión uniaxial: un estudio in situ con SAXS}

Resumen

Palabras clave

\begin{abstract}
La compleja estructura de los aerogeles híbridos orgánico/inorgánicos está compuesta por una fase inorgánica de sílice, unida mediante enlaces covalentes a una red de cadenas orgánicas. Se han estudiado composites híbridos convencionales y bioactivos, esto es, con una fase activa de calcio añadida. En este trabajo se ha investigado la relación entre la respuesta mecánica y la nanoestructura, con ayuda de un portamuestras específicamente diseñado para el estudio in situ de muestras bajo compresión uniaxial, a la vez que se obtiene el espectro de rayos-X a bajo-ángulo de radiación sincrotrón (SAXS). Los elementos estructurales se pueden describir como núcleos particulados de sílice rodeados de las cadenas orgánicas. Estas, se comprimen en la dirección paralela a la carga pudiéndose establecer una relación entre la compresión uniaxial macroscópica y la deformación de las partículas y poros que forman la estructura.
\end{abstract}

Aerogel híbrido; Bioactividad; Nanoestructura; Compresión uniaxial; SAXS.

\section{INTRODUCTION}

The complex structure of hybrid organic/inorganic aerogels is composed by an inorganic phase covalently bonded to organic chains forming a copolymer ${ }^{[1-3]}$. Depending on the relative organic content, the mechanical behaviour changes drastically, tuning from a brittle solid to an elastomeric one. This fact was known since Mackenzie determined the critical concentration of $40 \mathrm{wt} . \%$ of organic content on xerogels where the change of the mechanical properties could be found ${ }^{[4]}$. Recently, this change on the mechanical behaviour at $40 \mathrm{wt} . \%$ of organic content was also verified for aerogels ${ }^{[5]}$. This change can be explained in terms of the structure: for low organic contents (lower than $40 \mathrm{wt} . \%$ ) the matrix host is formed by the silica gel whereas the organic phase acts as embedded phase. But the percolation threshold of the organic phase can be found precisely at $40 \mathrm{wt} . \%{ }^{[6]}$, so for higher organic contents, the organic phase is forming the host matrix where embedded silica gel clusters can be found.

As the organic polymer interlinks the silica clusters, the aerogel hardness and the elastic modulus fall down drastically. These hybrid aerogels are viscoelastic regarding to the time dependence of the

\footnotetext{
* Instituto de Ciencia de Materiales de Sevilla, CSIC-US, Av. Américo Vespucio 49. 41092 Sevilla. victor.morales@icmse.csic.es.

** Dpto. Física de la Materia Condensada, Facultad de Ciencias Universidad de Cádiz. 11580 Puerto Real, Cádiz. nicolas.rosafox@uca.es.

*** Dpto. Física Aplicada, CASEM Universidad de Cádiz.11580 Puerto Real, Cádiz. manolo.piniero@uca.es.

**** Dpto. Física de la Materia Condensada, Facultad de Física Universidad de Sevilla. 41012 Sevilla. luisesquivias@us.es.
} 
stress at fixed strain (relaxation) and of the strain at fixed stress (creep). The mechanical properties of these aerogels are a combination of the stiffness of the pure silica aerogel and the elasticity of the polymer chains, giving a viscoelastic solid. As a first process of the mechanical response, the decrease of the $\mathrm{Si}$ $\mathrm{O}-\mathrm{Si}$ bond angle of the polymeric chain can be considered. Under load the polymer chain behaves a spring (elasticity). As a second process, the tension produced between the compressed polymers pushing the silica clusters, penetrating inside and adapting to the porosity should be considered. This process can be assumed as a dashpot (viscosity). At this stage the crosslinking degree of the polymer chains and the micropores can play an important role in the scattered intensity. This complex behaviour can be described in terms of combined dashpot-spring models, as the Burger's model, a combined rheological Kelvin and Maxwell models ${ }^{[7]}$.

When a calcium rich phase is embedded into this aerogels, as for example wollastonite $\left(\mathrm{CaSiO}_{3}\right)$, they turn bioactive ${ }^{[8]}$. Adding network modifiers as MTES can help to tune the mechanical properties as whished. Combining the bioactivity of these samples, their mechanical behaviour (similar to those of the human cancellous bone) and their texture (that allows them to be vascularized), a potentially material for implants and bone substitution is in progress.

\section{METHODS}

\subsection{Sample synthesis}

TEOS (tetraethoxysiloxane) a silicon alkoxide, easily polycondenses to form a 3D entangled network. Polydimethylsiloxane (PDMS) a hydroxyl terminated polymer has been added to tune the mechanical behaviour. Some aerogels were doped with wollastonite $\left(\mathrm{CaSiO}_{3}\right)$ synthetic powders $(350 \mathrm{~nm}$ average size) in order to study their mechanical behaviour as bioactive materials. Finally, we have also modified the inorganic silica network with methyltriethoxysiloxane (MTES), an organosilicon compound. Reactions were assisted by high power ultrasounds $\left(0.6 \mathrm{~kJ} / \mathrm{cm}^{3}\right)$. The resulting gels were dried under supercritical conditions of the etanol $\left(240^{\circ} \mathrm{C}\right.$, $64 \mathrm{~atm}$ ) to obtain a monolithic aerogel. As a provision for the mechanical test, the samples were made as cylinders $18 \mathrm{~mm}$ long and $8 \mathrm{~mm}$ diameter approximately. More details of the sample synthesis can be found in prior references ${ }^{[9]}$.

Sample notation is PDMS $x x$, where ' $x x$ ' indicates the weight percentage of the organic phase regarding to the silica gel, and for bioactive samples,
PDMS $x x$ Cayy, where ' $y y$ ' indicates the $\mathrm{CaO}$ weight percentage present in the sample, regarding to the total silica of the sample (silica gel and silica from wollastonite). Samples with modified silica network with MTES were only synthesized with and MTES:TEOS volume ratio of 10:1.

\subsection{Synchrotron experimental set-up}

SAXS experiments were made at the European Synchrotron Radiation Facility in Grenoble (France), in the BM16 workstation. A photon energy of $12.684 \mathrm{keV}(\lambda=0.978 \AA)$ was used. With the experimental set-up of the workstation, the $q$-range covered in the experiment was $0.06 \mathrm{~nm}^{-1}$ to $2 \mathrm{~nm}^{-1}$. Scattering patterns were obtained in a CCD camera of $2048 \times 2084$ pixels, and $79.35 \mathrm{~m}$ size each. Reference sample of silver behenathe was used to have an accurate calibration of the sample-detector distance, the tilt angle, and the beam centre.

\subsection{In situ uniaxial compression}

We have designed a specific sample-holder to measure in situ the uniaxial compression of the aerogel (Fig. 1). The sample is placed between two horizontal loading plates where the load applied on the sample is controlled by means a step screw ( $1 \mathrm{~mm}$ by turn), knowing previously its experimental stress-strain curves. Sample-holder was mounted on a motorized

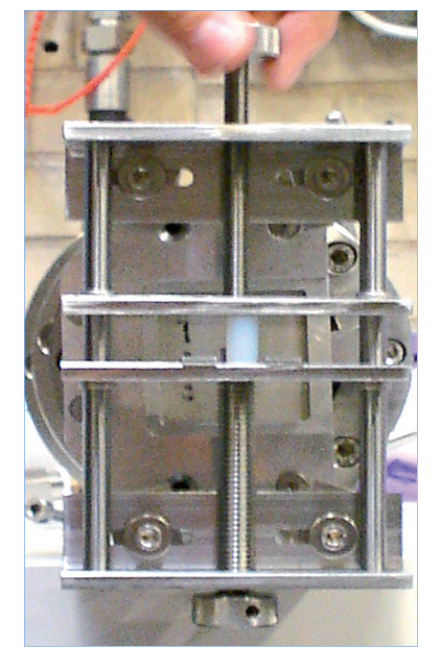

Figure 1. Sample-holder designed to study samples with synchrotron radiation under in situ uniaxial compression.

Figura 1. Portamuestras diseñado para el estudio con radiación sincrotrón in situ bajo compression uniaxial. 
aluminium frame. Two lateral guides assure the parallelism of the horizontal plates. With this device, the applied load can be known at any moment and small angle $\mathrm{x}$-ray scattering experiments could be performed under compression.

Samples were measured first without compression and then under several loads determined by its deformation controlled by the step screw. Spectra, under uniaxial compression, show anisotropic butterfly patterns due to the rearrangement of the polymer chains ${ }^{[10]}$. As a consequence different spectra are obtained along the parallel and perpendicular directions regarding to the direction of the load.

\section{RESULTS AND DISCUSSION}

\subsection{Conventional hybrid samples}

As a general rule, no significant change was observed in the nanostructure, in the direction perpendicular to the load, so the following studies are focused on the changes observed in the direction parallel to the load. That is, no changes are observed in the sizes and shapes of the particles and pores in the perpendicular direction to the load caused by macroscopic deformation.

Scattered intensities of organic/inorganic aerogels were measured. In all cases a wide Guinier region could be found in the intensity curves (Fig. 2), revealing a homogeneous particle distribution ${ }^{[11]}$. Along the parallel direction, a reduction in the Guinier radius is apparent from the figure 2, from 5.8 $\mathrm{nm}$ to $3.8 \mathrm{~nm}$ for PDMS20 and from $7.5 \mathrm{~nm}$ to 3.9

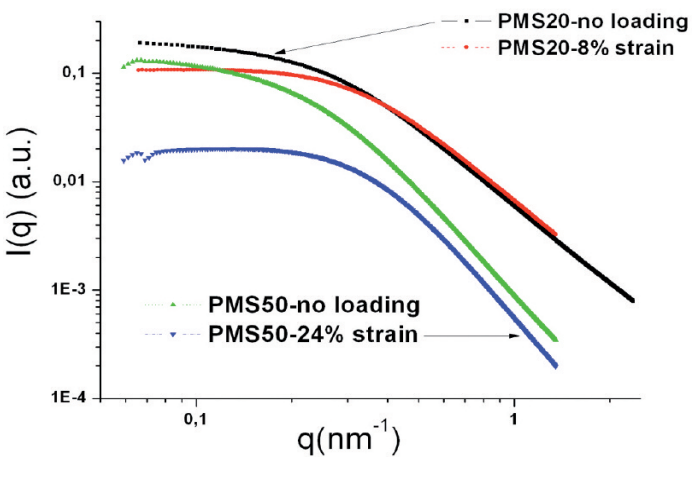

Figure 2. Scattered intensities by hybrid organic/inorganic aerogels, for different organic contents and different strains.

Figura 2. Intensidades difundidas por aerogeles híbridos orgánico/inorgánico, con diferente contenido orgánico y a diferentes deformaciones. $\mathrm{nm}$ for PDMS50. The calculated values of sample PDMS20 are plotted in figure 3, for different strains.

The macroscopic uniaxial compression reduces the size of the scatterers due to the folding of the organic chains that surround the silica gel clusters. The greater is the organic content, the lower the Young's modulus is, and so straining the complete structure is "easier". On the contrary, for low organic contents, the organic chains surrounding the silica gel particles fold and change their positions within the porosity, changing the particle size.

A full analysis of the different models was performed for sample PDMS20 under different strains. Guinier radius $R_{\mathrm{G}}$ was compared with other scattering models, as chord length (lc), sphere model $(R)$, random coil model (Rc) and fractal model (D). In figure 3 , these different parameters are plotted versus strain. The difference between sphere model and Guinier model indicates that not well defined spheres are scattering the incident radiation. In addition the chord length, which stands for size of the pores and the size of the particles, remains almost constant, so given a macroscopic strain, pores change significantly and particles do not so. This result supports the hypothesis of having big differences between pores strain and particles strain. Finally, radii of the random coil model also drop less than Guinier model, as it corresponds to the entanglements of the organic chains.

In figure 4, the relationship between macroscopic strain and the nanostructure deformation for three different samples are plotted. A linear relationship is found between both macroscopic and nanometric strains for sample PDMS20. For samples PDMS30

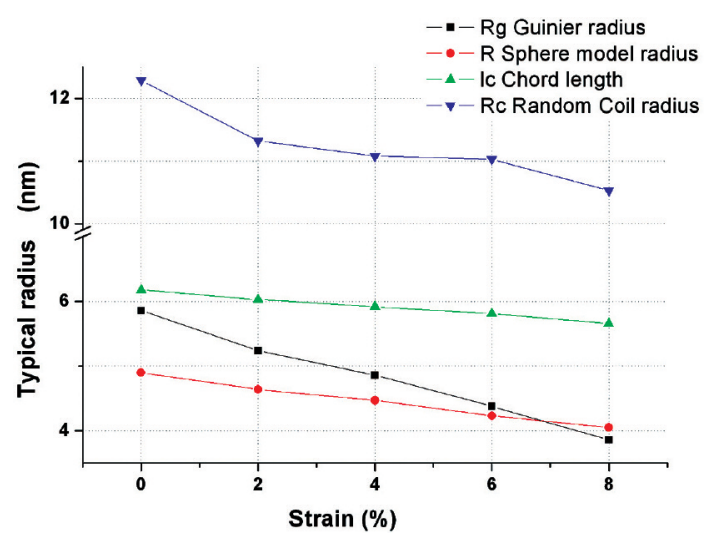

Figure 3. Characteristic radii derived from different models in sample PDMS20 for different uniaxial strains.

Figura 3. Radios característicos derivados de diferentes modelos en la muestra PDMS20 a distintos esfuerzos uniaxiales. 


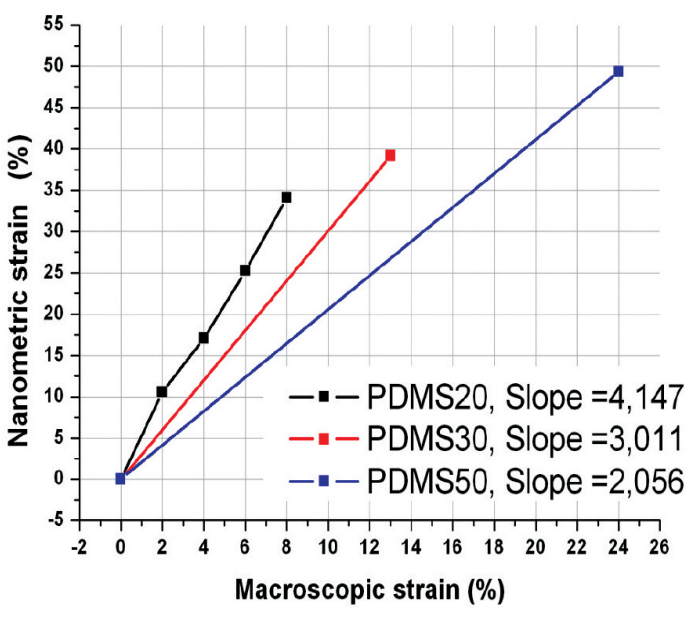

Figure 4. Relationship between the macroscopic applied strain and the deformation of the Guinier radii $(\mathrm{Rg})$ of the particles.

Figura 4.Relación entre la deformación macroscópica aplicada y la deformación del radio de Guinier de las partículas.

and PDMS50, linear behaviour is assumed. The higher is the organic content, the lower is the slope.

The slope greater than 1 for all samples can be explained assuming that the pores are the scatterers revealed by the SAXS experiments. In this regard, the strain of the pores is greater than the macroscopic strains, and therefore the particles forming the structure do not strain so much. In the case of sample PDMS20, the $35 \%$ of compression will be the reduction of the size of the pores, and therefore in this range of macroscopic strains $(<10 \%)$ the silica particles will not be strained. The decrease of the pore size occurs due to the folding of the organic chains that surround the silica clusters. But the nitrogen physisorption results ${ }^{[5]}$ showed a well defined monodisperse pore size distribution around $2.0 \mathrm{~nm}$ of pore radius corresponding to a Guinier radius of $2.6 \mathrm{~nm}$, quite far away from the $5.8 \mathrm{~nm}$ obtained from SAXS (Fig. 3). This inconsistency between SAXS and nitrogen physisorption results pore radii could be explained in terms of the scattering contrast between the organic chains and the silica matrix, and related with the thickness of the rim of the organic chains that surrounds the silica clusters. In this way, an empirical relationship can be derived from the experimental results as:

$$
\varepsilon_{\text {nano }}\left(\chi_{\text {org }}, \varepsilon\right)=\left(5.29-0.06 \chi_{\text {org }}\right) \varepsilon
$$

where, $\varepsilon$ is the macroscopic strain, $\varepsilon_{\text {nano }}$ is the strain of the scatterers and $\chi_{\text {org }}$ is the organic content, in wt. \%.
Regarding to the power law decay of the non-loaded curves, an increase of the exponent in the high $q$-region, from 2.3 to 3.5 is observed when the sample goes from $20 \mathrm{wt} . \%$ to $50 \mathrm{wt} . \%$ of PDMS. This behaviour reveals a crossover between a mass to a surface fractal, although the power law q-range is very narrow to consider the solid as a fractal structure, the above result allows to consider the contribution of the polymer chains surrounding the silica clusters, as the polymer content increases. In addition, this is coherent with the change in the role of the two phases for these two organic contents: in the first case, the silica gel (mass fractal) is the host of the composite whereas in the sample with $50 \%$ of organic content, the host is formed by the entangled organic chains.

\subsection{Bioactive hybrid organic/inorganic aerogels}

In the bioactive aerogels, with wollastonite powders are dispersed on the liquid mixture, prior to the gelation process, the scattering intensities show a very different curve, as it is depicted in the figure 5 for the sample PDMS20CaO9.

Parallel and perpendicular scattered intensities can be compared, with and without load in figure 5 . In the spectra corresponding to the parallel direction to the load (Fig. 5, top) it is apparent the lost of the good Guinier region, as the low $q$-range reaches sizes greater than $100 \mathrm{~nm}$, close to the size of the wollastonite grains ( $\approx 350 \mathrm{~nm}$ radius). The curves present a power law slope of 2.3, in agreement with the curve corresponding for the sample PDMS20. So we could assume that the nanostructure below $50 \mathrm{~nm}$ of the hybrid porous matrix is analogous to the obtained without embedded wollastonite.

When the aerogel is uniaxially compressed, the decrease of the intensity begins to develop a smooth structure factor at $q=0.15 \mathrm{~nm}^{-1}$. And at high strains (16\%), the particles (or pores) forming the matrix can be clearly seen, as the organic chains fold and readapt to the porosity of the clusters. In addition, at very low q values, a larger structure starts to be revealed, probably due to the compression of the matrix surrounding the mineral grains. Ultra-small angle $\mathrm{x}$-ray scattering experiments are necessary to resolve this aspect.

In the perpendicular direction (Fig. 5, bottom), no significant change was observed but the decrease of the intensity due to an increase of the density with the compression. Neither increase of the size of the scatterers is observed in this direction.

SAXS experiments were also performed on samples with $30 \%$ of calcium content but no major 
HYBRID AEROGELS AND BIOACTIVE AEROGELS UNDER UNIAXIAL COMPRESSION: AN IN SITU SAXS STUDY AEROGELES HÍBRIDOS Y AEROGELES BIOACTIVOS EN COMPRESIÓN UNIAXIAL: UN ESTUDIO IN SITU CON SAXS
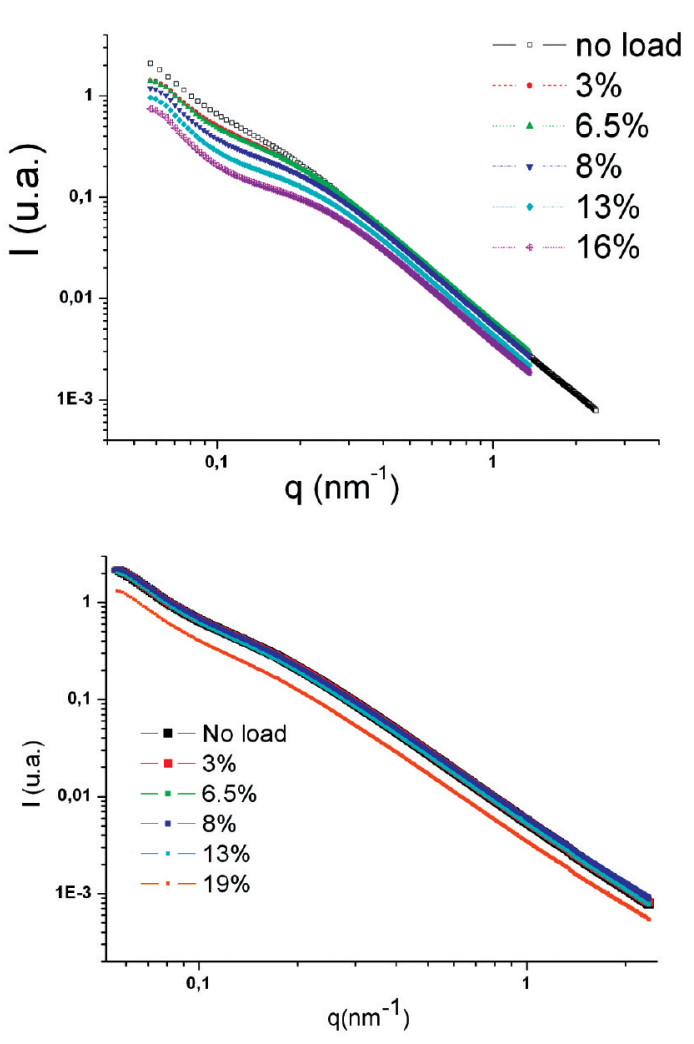

Figure 5. Scattered intensities for bioactive hybrid organic/inorganic aerogel PDMS20Ca9. Top: parallel direction to the load; Bottom: perpendicular direction.

Figura 5. Intensidades difundidas por el aerogel bioactive orgánico/inorgánico PDMS20Ca9. Arriba: dirección paralela a la carga. Debajo: dirección perpendicular.

difference was observed (not shown), regarding to the previous one. Again, the embedded wollastonite grains hide the structure factor of the porous matrix, behaving in a similar way as the 9 wt. $\mathrm{CaO}$ samples.

\subsection{Relaxation tests}

The bioactive hybrid organic/inorganic aerogels were submitted to a $12 \mathrm{~h}$ relaxation tests, measuring SAXS intensities each hour. The applied strain was $18 \%$. In figure 6 , the set of 12 curves is shown. It can be clearly seen how there is no change in the shape of the scattering curve for twelve hours of test. So, the nanostructure rests constant once it is deformed instantaneously. This can be interpreted in terms as, in this time and length scale, the particles are deformed, the organic chains folded and relocated within the meso- and micro-porosity of the gel, acting

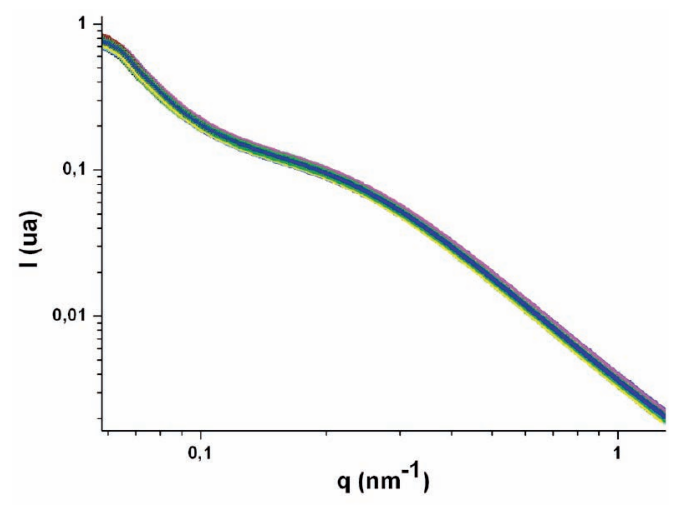

Figure 6. Set of twelve curves obtained in a $12 \mathrm{~h}$ relaxation test with a $18 \%$ strain. The sample has a $20 \%$ wt. of organic content and a $9 \%$ wt. of $\mathrm{CaO}$.

Figura 6. Conjunto de doce curvas obtenidas durante 12 h en relajación con una deformación del $18 \%$. La muestra tiene $20 \%$ en peso de contenido orgánico y $9 \%$ en peso de CaO.

as the rheological spring. Then, the viscous flow of the viscoelastic behaviour is performed at larger scales, that is, by the relative diffusion of the clusters among each others.

\subsection{MTES/TEOS/PDMS aerogels}

bioactive

Methyltriethoxysilane (MTES) was used to build the inorganic matrix by copolymerization with the TEOS. This precursor is known to be a modifier of the mechanical properties in the inorganic aerogels, increasing significantly the rupture strain of the samples. As an example of this fact, it can be seen that the sample PDMS20Ca9MTES admits up to $46 \%$ strain, instead of the $16 \%$ obtained for the sample without MTES.

The obtained scattering curves and derived Guinier radii and sphere model radii are plotted in the figure 7 . If the initial state showed no well defined Guinier region, it clearly appeared with the applied strain. The compression of the organic chains and the non-linked terminal methyl groups yield a more homogenous particle shape, developing a Guinier region. The radii obtained by the Guinier model and the sphere model show a similar decrease, supporting the idea of quasispherical scatterers (particles or pores). The size of the scatterers (particles or pores) decreases significantly, from $22.5 \mathrm{~nm}$ to $12.6 \mathrm{~nm}$, very similar to macroscopic strain. In this case, the MTES modifies the inorganic skeleton allowing it to deform as much as the 


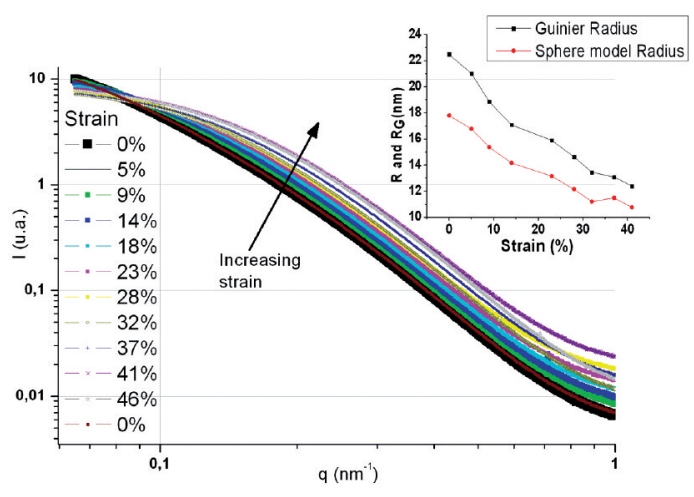

Figure 7. Scattering curves of the sample PDMS20CaO9MTES for different strains, and at the final relaxed state (brown line) overlapping the initial state (black line). Inset: Guinier radii and the sphere model radii of each different strain.

Figura 7. Curvas de difusión de la muestra PDMS20CaO9MTES para diferentes deformaciones, y y al final el estado relajado (línea marrón) superponiendose al estado inicial (línea negra). En el interior: radio de Guinier y radio del modelo esférico de cada diferente deformación.

macroscopic strain. Final behaviour of the Guinier radii for large strains $(>30 \%)$ points to the existence of a hard core probably made by silica of around $10 \mathrm{~nm}$ radius. More experiments on larger strains should be done to resolve this aspect.

Finally, once the strain is released, the final state shows exactly the same scattered curve as the initial state. Thus, non plastic deformation was observed at this nanometric scale.

\section{CONCLUSIONS}

- The effect of macroscopic strain on the nanostructure affects only in the direction parallel to the load. In the perpendicular direction, no important change can be found. Consequently, no elongation of the particles is found, but only compression due to the applied load. The organic chains fold and adapt within the gel porosity.

- The applied strains allows us to establish an empirical relationship between the macroscopic and nanometric strains. Pores deform more than the macrostructure, so unavoidably, the inorganic skeleton deforms less.

- Bioactive hybrid aerogels present similar texture than the hybrid aerogels. Besides, they present similar structural behaviour under uniaxial stress, in this nanometric length scale.
- Relaxation test on the bioactive aerogels proved that viscoelastic behaviour concerns larger scales and it does not involve changes in the nanostructure. No plastic deformation could be found in the nanostructure as well.

\section{Acknowledgements}

We acknowledge the European Synchrotron Radiation Facility (ESRF) for provision of synchrotron radiation facilities and we would like to specially thank Mr. F. Fauth for assistance in using beamline BM16. The authors are also grateful to the Consejería de Innovación Ciencia y Empresa of the Junta de Andalucía (Spain), for supporting this work with the annual grant TEP115 and to the Ministerio de Ciencia e Innovación of the Spanish Government for the grant PIA42008-31. V. MoralesFlórez thanks also to the JAE program of the Consejo Superior de Investigaciones Científicas (CSIC) for the financial support and to Santiago Domínguez Meister for his advices and discussions.

\section{REFERENCES}

[1] C. Sanchez and B. Lebeau, MRS Bulletin (2001) 377-387.

[2] O. Foussaier, M. Menetrier, J.-J. Videau and Duguet, Mater. Lett. 42 (2000) 305-310.

[3] V. Morales-Flórez, J. A. Toledo-Fernández, M. Piñero, N. de la Rosa-Fox and L. Esquivias, Proc. XI Int. Conf. Physics Non-Crystalline Solids, Rodas, Greece, 2006, p. 337.

[4] J. Mackenzie, Q. Huang and T. Iwamoto, J. SolGel Sci. Tech. 7 (1996) 151-161.

[5] V. Morales-Florez, PhD Thesis, Universidad de Sevilla, 2007.

[6] V. Morales-Florez, J.A. Toledo-Fernández, N. de la Rosa-Fox, M. Piñero and L. Esquivias, J. SolGel Sci. Tech. 50 (2009) 170-175.

[7] S.B. Adalja and J.U. Ataigbe, Polymer Composites 23 (2002) 171-181.

[8] L. Esquivias, V. Morales-Florez, M. Piñero and $\mathrm{N}$ de la Rosa-Fox, J. Non-Cryst Solids 351 (2005) 3.347-3.355

[9] J. A. Toledo-Fernández, R. Mendoza-Serna, V. Morales-Flórez, N. de la Rosa-Fox, A. Santos, M. Piñero and L. Esquivias, Bol. Soc. Esp. Ceram. Vidrio 46 (2007) 138-144.

[10] N. de la Rosa-Fox, V. Morales-Florez, J.A. ToledoFernández, M. Piñero, L. Esquivias and U. Keiderling, J. Sol-Gel Sci. Tech. 45 (2008) 245-250.

[11] O. Glatter and O. Kratky, Small Angle X-Ray Scattering, Academic Press, London, England, 1982, pp. 119-167. 